\title{
PARTICIPAÇÃO DO CEREBELO NA PATOGENIA DO CÂNCER
}

\author{
Noemio Weniger *
}

Esta nota preliminar pretende chamar a atenção para uma doutrina de Augusto Comte sôbre as funções do cerebelo, a qual, diante dos fatos clínicos e anátomo-patológicos que se vêm progressivamente acumulando, merece ser lembrada e difundida. Essa doutrina atribui ao cerebelo, entre outras, as funções de presidir às atividades vegetativas e sexuais. Tal concepção baseia-se nas idéias de Gall, que atribuía a função sexual à totalidade do córtex cerebelar. Augusto Comte, baseado na zoologia comparativa, admitia que a regência daquela função compete ao córtex dos hemisférios cerebelares; ao vérmis atribuiu outra função, qual seja a de regular os fenômenos gerais de nutrição. Assim, segundo a concepcãa de Augusto Comte, havendo intima solidariedade entre os instintos de nutrição e sexual, ambos têm sede no mesmo órgão, o cerebelo. Tais funçōes, porém, são distintas entre si e não são redutiveis uma à outra.

Essa concepção que situa duas funçōes distintas no cerebelo foi primeiramente confirmada pela anatomia comparada ao estabelecer a divisão dêste órgão em paleocerebelo e neocerebelo e, depois, pela clínica e pela experimentação em animais. A cuidadosa revisão dos dados experimentais permitiu verificar que, nos animais, as lesões do cerebelo determinavam distúrbios nas manifestações instintivas de nutrição $\mathrm{c}$ de sexualidade.

Mathias Duval (cit. por Nilo Cairo ${ }^{4)}$ dizia a êste respeito: "Apesar das experiências e observacōes contraditórias de Leuret, de Combette e de Vulpian, encontramos diversos argumentos tírados da observacão e da clínica por Budge e Valentin, Wagner e Lussana, que dão alguma aparência de realidade à hipótese de Gall, que fazia do cerebelo o centro do amor físico, da paixão erótica, e assinalam a êste órgão um papel importante nas manifestações e no exercicio do instinto genital". Nilo Caíro", em minuciosa análise, disse: "Sabe-se que Comte localizava no vérmis a sede do instinto nutritivo ou da conservação individual, e nos lobos laterais a do instinto sexual ou da conservação da espécie. E êle compreendia por instinto o estado de atividade de um certo número de células nervosas associadas entre si, num centro, que dá lugar a um impulso emocional traduzindo-se exteriormente por certos atos voluntários: assim, o instinto nutritivo nos impele à apreensão e à ingestão dos alimentos, e o instinto sexual ao coito. A essa concepção o seu autor ajuntou que, por intermédio de fibras nervosas tróficas, o instinto nutritivo agia sôbre a nutrição geral dos tecidos do corpo, e o instinto sexual, sôbre os órgãos genitais. Ora, quer-nos parecer que essa concepçāo esté pouco mais ou menos de acôrdo com os resultados das pesquisas modernas sôbre o cerebelo tónico,

* Psiquiatra do Hospital de Juqueri (São Paulo); ex-estagiário do Hospita Júlio de Mattos (Diretor: Prof. H. J. Barahona Fernandes), Lisboa. 
pelas seguintes razōes: o cerebelo age efetivamente sôbre o corpo pelas vias cerebelomedulares (aça o trófica de Luciani e particularmente tônica de A. Thomas sôbre os músculos) e esta ação se revela por perturbações tróficas (de que a tonicidade dos músculos é um caso particular) e por perturbaçōes incontestáveis na esfera genital, ainda que muito mais raras; o cerebelo age, ainda segundo A. Thomas, pelas vias cerebelocorticais, sôbre o cérebro e, ainda aqui, as perturbaçōes psiquicas observadas são perturbaçōes do instinto de conservação (terrores, pusilanimidade, desconfiança, apatia, etc.) ou do instinto sexual (aversão sexual, exaltações genitais). Assim, o cerebelo intervém nos movimentos (voluntários ou reflexos) por sua ação tônica, que é trófica, sôbre a elasticidade muscular: êle é, pois, motor, porque é o centro psíquico trófico do organismo e nada mais; ou, por outras palavras, sua açāo de regularização tônica é um resultado particular, lógico, da sua função mais geral de centro psiquico que regula a nutrição. Em suma, em vez de infirmar, a concepçâo moderna que se faz da funcão cerebelosa confirma a localização de A. Comte do instinto nutritivo no cerebelo" (págs. 300-301, grifos e parênteses do original).

Ainda no dominio das reaçoes instintivas, devemos lembrar os dados obtidos por Anibal Silveira em 1942, segundo comunicaçāo pessoal registrada por Vizzotto e col. ${ }^{17}$. Baseado na concepçâo de A. Comte sôbre as funções cerebelares, previu Anibal Silveira que a seç̧ão das conexões hipotálamo-cerebelares deveria abolir a "sham-rage", o que de fato se deu, ficando assim demonstrado neurofisiologicamente que as reações psicológicas de defesa geralmente atribuidas ao hipotálamo estão, na realidade, subordinadas ao cerebelo. Moruzzi "2 também demonstrou que a "shamrage" é subordinada à regulação cerebelar: procedendo à estimulaçâo elétrica do cerebelo durante o acesso de cólera, verificou que "a inibiçāo da atividade diencefálica é observada apenas quando o estimulo cerebelar incide durante a irrupção do acesso de cólera; embora raramente seja observada a supressão completa do comportamento enfurecido, é comum ocorrer nitido decréscimo nas manifestações somáticas e autonômicas da cólera" (págs. 85-86, grifo nosso).

O progredir das experiências, não só pela mutilação como pela estimulação de diversas zonas encefálicas, veio mostrar que o cerebelo está integrado em sistema geral córtico-subcortical. Primeiramente, Dusser de $\mathrm{Ba}$ renne evidenciou a existência de uma zona inibidora cortical (4s), tendo ulteriormente seus colaboradores demonstrado que outras regiōes tinham esta propriedade inibidora: área $2 \mathrm{~s}$, zonas perissensoriais, cingulo, hipotálamo, substância reticulada e córtex cerebelar. Portanto, há dois sistemas de associações cerebelo-cerebrais: o referido acima, demonstrado por Dusser de Barenne e colaboradores e outro, já conhecido há mais tempo, que é o sistema cerebelo-fronto-ponto-rubro-espinal; aquêle, mais diretamente ligado às funções vegetativas, êste mais ao tono muscular e à motilidade. Por outro lado, o cerebelo está ìntimamente correlacionado com a região hipotalâmica, já bastante conhecida como reguladora das funçốes vegetativas de nutrição, de maturaçāo sexual e relativas ao funcionamento dos aparelhos circulatório, respiratório e digestivo. As ligações intimas da regiāo hipotalâmica com o cerebelo - vérmis e hemisférios - mostram que não se trata de núcleos autônomos, mas integrados nos sistemas paleocerebelar e neocerebelar.

Baseando-nos na doutrina sôbre as funçôes instintivas do cerebelo e, ao mesmo tempo, considerando a desnutrição e a caquexia que ocorrem no câncer, formulamos a hipótese de que existiriam correlaçōes íntimas entre êste órgão e os processos neoplásicos. Essa suposição fêz con- 
vergir nossa atenção para os diversos aspectos anátomo-clínicos do cerebelo, permitindo verificar, desde logo, a freqüência com que a literatura médica registra casos de atrofias cerebelares associadas aos carcinomas viscerais. Tais achados histopatológicos já tinham chamado a atenção dos neurologistas e neuropatologistas, a ponto de autores como Brouwer e Biémond ${ }^{3}$, em minuciosa revisão publicada em 1938, admitirem uma forma especial de atrofia cerebelar característica das neoplasias viscerais, atribuindo-a à ação de uma toxina cancerosa.

Da análise das observações publicadas ainda surgia outro dado importante em apoio a essa suposição: êsse tipo de atrofia cerebelar não só era freqüentemente associado com carcinomas viscerais, mas, entre êsses, os carcinomas dos ovários eram os mais comuns (Greenfield ${ }^{6}$ ). Fundados em rigorosas verificaçōes histopatológicas, êstes mesmos achados vêm sendo relatados por vários neurologistas e neuropatologistas, entre os quais Zülch ${ }^{19}$, Ivan Bertrand e Godet-Guillain ${ }^{1}$, Leigh e Meyer 7 e Miller ${ }^{11}$.

Considerando o que Brouwer e Biémond 3 já haviam salientado quanto à freqüência das atrofias cerebelares no decurso dos cânceres viscerais, Ivan Bertrand e Godet-Guillain, em 1942, resolveram, segundo sua própria expressão, "inverter os dados do problema, pesquisando a existência de possiveis alterações cerebelares em todos os cancerosos mortos sem sinais neurológicos". Das verificações realizadas em 16 casos examinados, resultou que 14 dêsses pacientes apresentaram um "processo degenerativo estritamente celular, interessando sobretudo a camada granular do cerebelo e o complexo olivar do bulbo". É interessante lembrar que Ivan Bertrand e Godet-Guillain consideram admissivel que tais lesōes, da mesma forma que aquelas encontradas no cerebelo em casos de coma diabético, "sejam menos devidas a uma toxicose do que a distúrbios profundos no metabolismo".

A êste propósito devemos referir que, já em 1937, Aníbal Silveira, no Hospital de Juqueri, interpretava a açāo do coma insulínico como falência do instinto de nutrição, por sua vez reconhecido como função cerebelar. Esta ação se processaria através dos núcleos vegetativos do hipotálamo, o que levou Anibal Silveira a supor que êstes últimos se apresentassem lesados nos pacientes que viessem a falecer de coma prolongado. Esta hipótese foi naquela ocasião confirmada, histologicamente, por Yahn e Pupo 18: "Por fim, queremos assinalar ainda aqui que os nossos achados histopatológicos, pela sua localização e gravidade, constituem contribuição importante em favor das idéias de A. Silveira, segundo as quais as perturbações provocadas pela insulina em doses maciças se manifestam primàriamente sôbre as regulações vegetativas, de sede diencefálica; o transtôrno destas repercutiria sôbre as funções de órgãos corticais; tais ações e reações se efetuariam, quer pelo contrôle do metabolismo celular, quer mediante regulações nervosas (centro encefálico regulador das funções corticais)".

Isso foi confirmado, ulteriormente, tambẻm em relação ao cerebelo: é o que se vê em trabalho de Ivan Bertrand e Tiffeneau ${ }^{2}$, onde são relatadas lesões cerebelares no coma diabético. O mesmo tem sido verificado mais 
recentemente, salientando-se, entre outros, o trabalho de Leigh e Meyer ?, onde é referida a degeneração da camada granular do cerebelo não sòmente no coma hipo e hiperglicêmico, como também em 8 casos de carcinoma visceral e 4 de idiotia amaurótica. É, ainda, também com relação ao coma e à chamada carcinotoxicose, o que confirmam autoridades como Ule ${ }^{16}$.

Diversos investigadores tiveram a sua atenção voltada para a correlação entre câncer e cerebelo, correlação demonstrada não sòmente no campo histológico mas também no plano clínico. Todos os casos de câncer relatados em trabalho de Russel Brain e col. ${ }^{13}$ apresentavam sintomas cerebelares, sendo que, em três, tais sintomas ocorreram precocemente. Segundo êstes autores, "a revisão da literatura mostra alta incidência de carcinoma entre os casos de degeneração cerebelar cortical subaguda". E acresecntam: "Dos casos que evoluíram em 2 anos, mais de $2 / 3$ tinham sido de carcinoma, ainda que êste não fôsse sempre clinicamente evidente. As formas de decurso mais crônico da degeneração cerebelar não mostram essa correlação. Ao considerar a patogenia da doença, salienta-se a especial vulnerabilidade das células de Purkinje aos tóxicos extrinsecos ou às perturbaçōes metabólicas intrínsecas. Mas nisto não se encontra explicação para a raridade da doença". Mais recentemente, Russel Brain e Strauss ${ }^{14}$ deixaram bem explicito seu pensamento nos têrmos seguintes: "A relação de tempo entre o início dos sintomas neurológicos e os devidos ao próprio carcinoma é importante e às vêzes mesmo desconcertante. Por vêzes, os sintomas do carcinoma aparecem primeiro e os sinais neurológicos vêm a ser encontrados mediante o exame clinico de rotina ou, então, só surgem mais tarde. Freqüentemente, entretanto, são os sintomas da neuropatia que levam o doente a ser examinado, e a pesquisa ulterior é que vem a revelar o carcinoma. É isto o que parece ocorrer comumente nos casos de degeneração cerebelar subaguda associada ao carcinoma ovárico. Um caso pelo menos já foi observado, no qual a paciente apresentou a neuropatia e obteve boa remissão, antes de manifestar sintomas do carcinoma. Em outro extremo se situa um caso em que a paciente não apresentou a degeneração cerebelar subaguda até muitos meses após o ato cirúrgico que removeu o carcinoma do ovário".

Zülch ${ }^{19}$ acentua a importância do estudo das atrofias cerebelares em face da eletividade com que alguns processos mórbidos repercutem sôbre o córtex dêste órgão, nomeadamente o câncer. A propósito de um caso que observaram e no qual havia sintomatologia cerebelosa subaguda em paciente portadora de câncer, Thomas e Chodoff 15 dizem: "Neste caso os dados clínico-neurológicos sugeriam tratar-se de um carcinoma extraneural sem lesōes metastăticas no sistema nervoso central, determinando sintomas neurológicos. Esta possibilidade deveria ser incluída no diagnóstico diferencial de todos os casos com sintomatologia de ataxia cerebelar subaguda. A utilidade dêste procedimento é indicada pelo presente caso, no qual a presença de uma síndrome cerebelar sem fatôres familiares ou tóxicos sugeria a pesquisa de um possivel processo maligno extracraniano, o qual foi encontrado".

Finalmente, cabe referir a pormenorizada análise que dèsse problema fêz Henry Miller 11, da qual extraímos os trechos seguintes: "Tem sido dada 
crescente atenção às complicações neurológicas de carcinomas viscerais, não atribuiveis a metastáses maciças através das meninges ou do sangue .... $O$ tema só assumiu importância clínica, entretanto, depois de ter sido verificado que os sintomas neurológicos podem aparecer muito antes da caquexia e que, de fato, muitas vêzes precedem por espaço de meses ou mesmo de um ano ou dois, a quaisquer manifestações clínicas da neoplasia" (pág. 298). Éste autor discrimina as complicações neurológicas associadas a cânceres viscerais em quatro tipos (neuropatia sensitiva primária, polineurite mista de tipo sensitivo-motor, degeneração cerebelar cortical subaguda, condiçóes obscuras rotuladas como miopatias).

A atrofia cerebelar verificada em doentes mortos em conseqüência de processos neoplásicos tem sido, em geral, atribuída à ação de uma "toxina cancerosa". No entanto, não haveria antagonismo entre a hipótese de "toxina cancerosa" e a possibilidade de o processo neoplásico ser secundário ao distúrbio cerebelar. Esta correlaçāo inversa, ao que nos parece, deve ser investigada, visto que algumas vêzes os sintomas cerebelares precedem, por espaço que vai de meses até dois anos, qualquer manifestaçāo clínica de neoplasia, conforme já foi referido.

O que importa para a concepção em causa é que as lesões cerebelares associadas ao carcinoma extra-encefálico são freqüentemente eletivas e, algumas vêzes, estritamente limitadas ao córtex cerebelar, conforme se pode verificar em alguns casos bem estudados, como em uma das observações de Brouwer e Biémond ${ }^{3}$, na qual a atrofia cerebelar estava associada a carcinoma do ovário. Malamud" referiu dois casos com atrofia limitada ao córtex do cerebelo, sendo uma de câncer pulmonar e outra de doença de Hodgkin.

Admitido que o cerebelo regula os instintos de nutrição e sexual e considerando, por outro lado, os fatos clínicos e anátomo-patológicos que vimos de expor, dirigimos a atençāo para possiveis sintomas subjetivos que fôssem caracteristicos dos pacientes sofredores de câncer e que se filiassem àquelas manifestações instintivas. Assim, a astenia, a anorexia e a caquexia, comuns nos casos de câncer, seriam atribuiveis a distürbios do instinto de nutrição.

Quanto aos distúrbios na esfera sexual, os dados são mais escassos, se bem que não menos significativos. Leshan e Worthington ${ }^{8}$, ao passar em revista a literatura relativa à personalidade como fator na patogenia do câncer, verificaram que podem ser assinaladas quatro linhas constantes de alterações, entre as quais se destacam os distúrbios sexuais. Se bem que, no trabalho dêstes autores, os distúrbios sexuais que precedem aos sinais clinicos de neoplasia, como nos demais estudos de indole psicossomática, sejam considerados como possiveis fatôres propicios, dentro da hipótese que sugerimos, êles poderiam ser sintomas precoces de alterações do cerebelo. $\mathrm{E}$ não são sòmente êsses os fatos que, a nosso ver, sugerem a necessidade de aprofundar mais o estudo dos distúrbios da esfera sexual nos cancerosos. 
Há a considerar, por exemplo, o caso do priapismo na leucemia; não obstante êste distúrbio tenha sido geralmente objeto de interpretação mecanicista, diante de tudo que até aqui expusemos parece-nos indicado aprofundar o seu estudo. Em relação a êsse sintoma, escreve Marañón 10: "El priapisom es bastante frecuente en la leucemia y puede ser tan doloroso que desespere al enfermo. A veces es el síntoma qu pone sobre la pista de la enfermedad, todavia en estado latente" (pág. 835). E pouco mais adiante, referindo-se ao priapismo senil: "Las causas locales antes expuestas, principalmente las prostáticas, pueden producir el priapismo senil, sobretodo, matutino. Pero, en la mayoría de los casos que he observado, se trataba de motivos nerviosos, ya por erotismo cerebral, senil, ya por lesiones nerviosas (estado lacunar, con lesiones principalmente cerebelosas o en el puente de Varolio)".

Assim, já existem fatos, tanto de ordem anátomo-patológica, como clínicos e também psicológicos, suficientemente sugestivos, que justifica ser considerada, nas pesquisas sôbre a patogenia do câncer, a concepção aqui exposta sôbre as funções instintivas do cerebelo, visto que é êste o órgão mais afetado e, algumas vêzes, o único, nos processos neoplásicos viscerais.

A concepção que relaciona ao cerebelo tôda a patologia do processo neoplásico não é incompatível com as demais hipóteses sôbre a etiopatogenia dêste último. O cerebelo, que, na concepção da escola positivista e de acôrdo com Aníbal Silveira, admitimos ser o responsável pela reação ao "stress", isto é, como o órgão de alarme na defesa do organismo, perderia o domínio da integração nutritiva ou trófica, possibilitando a eclosão do processo neoplásico; isto poderia ser devido a um esgotamento intrínseco do cerebelo, causado por uma condição geral do organismo ou por uma causa local que determinasse a libertação de uma região qualquer da regência nervosa central da nutrição.

Essa suposição parece-nos estar plenamente de acôrdo com as conclusões de Coujard ${ }^{5}$, o qual, esposando as concepções de Champy, conclui que o fato de ter conseguido produzir experimentalmente tumores malignos por lesão do sistema simpático e do diencéfalo, não incompatibiliza a interpretação neurotrófica com a admissão de outros fatôres etiológicos (pág. 88).

Ante o que acabamos de expor sôbre a participação do cerebelo na patogenia do câncer, parecem-nos cabiveis as seguintes ilações e sugestões:

1) Dados clínico-neurológicos e freqüentes achados histopatológicos registrados na literatura autorizam-nos supor que o cerebelo tenha participação mais ou menos constante na patogenia do câncer.

2) Tais dados, a nosso ver, devem ser avaliados à luz dos conceitos que atribuem ao cerebelo, além de funçôes reguladoras do tono e da atividade muscular, a função de órgão preposto ao instinto de nutrição e ao instinto sexual. 
3) Existem fatos anátomo-patológicos e clínicos que parecem justificar a necessidade de investigar com mais cuidado a ocorrência de distúrbios da esfera sexual nos cancerosos, como sejam: a) a elevada percentagem de associação de atrofia cerebelar com o câncer, principalmente do aparêlho genital; b) a freqüência do priapismo como um dos sintomas precoces da leucemia; c) a freqüência de lesōes cerebelares no priapismo senil; d) a freqüência com que são assinalados distúrbios sexuais no estudo da personalidade dos cancerosos.

4) Na investigação dos sintomas cerebelares (motores ou vegetativos) no decurso do processo neoplásico, deve ser considerada a eventualidade de estarem os distúrbios dos instintos nutritivo e sexual mascarados por outras condições, principalmente a idade e a caquexia.

5) Numerosos fatos anátomo-patológicos e clínicos, inclusive de ordem psicológica, parecem justificar seja retomada a verificação da histopatologia do cerebelo nos pacientes falecidos de câncer, da forma por que já o iniciaram Ivan Bertrand e Godet-Guillain. O exame histopatológico sistemático deverá abranger também outras zonas do encéfalo nos cancerosos, visto haver uma eletividade de diversos processos mórbidos caquetizantes e, especialmente, os do câncer, pelo cerebelo.

\section{RESUMO}

Baseando-se na doutrina de Augusto Comte sôbre a fisiologia cerebral, o autor aventa a hipótese de que o córtex cerebelar estaria envolvido na patogenia do câncer.

De acôrdo com a doutrina de Comte, o córtex do vérmis cerebelar seria responsável pela regência geral da nutrição, que se exprime no plano subjetivo da personalidade como instinto de conservação individual; o córtex dos hemisférios cerebelares seria preposto à regência do instinto sexual, não só quanto ao plano psicológico mas também quanto ao desenvolvimento do aparelho sexual. Os núcleos hipotalâmicos devem ser considerados como parte dêsse sistema.

Sendo o câncer, em última instância, considerado como uma desorganização do crescimento celular, era admissivel a presença de desordens cerebelares, tanto clínicas como histológicas, em pacientes de câncer, principalmente do aparelho genital em sentido lato. A revisão da literatura neuropatológica permite confirmar esta hipótese inicial: a maioria dos autores que relataram achados neuropatológicos associados ao câncer refere a ocorrência de atrofia das células de Purkinje, específica, subaguda e difusa.

Não obstante muitos autores considerarem êste processo como secundário ao carcinoma, a possibilidade de que a disfunção cerebelar seja causa da produção do câncer não fica excluída, pois vários pesquisadores têm assinalado que os sinais clínicos das lesões cerebelares aparecem, em muitos casos, antes que se manifestem os sintomas do câncer. 
Por outro lado, é sabido que, entre os sintomas que chamam a atenção no quadro sintomatológico dos cânceres, figuram a anorexia e a caquexia, ligadas à autoconservação (nutrição); ademais, são referidos o priapismo nos leucêmicos e distúrbios sexuais nos pacientes cancerosos, embora as alteraçóes na esfera sexual não tenham sido consideradas com a devida atenção.

O autor da presente nota sugere que: 1) pesquisas sejam orientadas no sentido de verificar se a desorganização cerebelar - manifestada clìnicamente em certos casos - é responsável pelo crescimento neoplásico; 2) que o exame clínico dos cancerosos seja completado com exame neurológico minucioso visando especialmente ao despistamento de alterações das funções cerebelares; 3 ) que na anamnese dos pacientes cancerosos seja investigada a existência de distúrbios ligados à esfera do instinto sexual.

\section{SUMMARY}

The sharing of cerebellum in the pathogenesis of cancer

Starting from Comte's doctrine on brain physiology, the author advances the views that cerebellar cortex should be involved in the pathogenesis of cancer.

According to that theory, the cortex of the vermis provides for the nutrition instinct, while neocerebellar cortex is responsible for the sexual drives. Hypothalamic nuclei are to be regarded as a relay in this system. Since cancer is recognized, in the last instance, as a disorganization of cellular growth, the author anticipated to find out cerebellar disturbances, clinical as well as histological, in cancerous patients; and this especially in cancer of the sexual organs at large.

A thorough search into the neuropathological literature has steadily supported this starting viewpoint. Most authors who have reported on neuropathological findings associated with cancer or reviewed the corresponding literature emphasized consistently a specifical "Purkinje's atrophy", subacute and diffuse in type. Even though in many of such papers it is termed a secondary process, with the carcinoma as the causal factor, the correlation is by no means excluded because many authors agree that clinical symptoms of cerebellar failure are present even long before the cancer symptoms may be detected.

The present writer calls attention to the mental symptoms pointing out to troubles of selfpreservation (nutritional) and/or sexual drives in the beginning of the clinical features, a fact which have not been stressed enough by the researchers. Chief aims of this preliminary report are to suggest: (a) that researches be directed towards finding out whether cerebellar disorganization - hence its clinical disturbances - are primarily responsible for cancer growth; (b) that clinical examination endeavor to detect fine neurological symptoms of cerebellar regulation; (c) that libido and erotic disturbances of behavior be investigated in the clinical history of cancer patients. 


\section{REFERENCIAS}

1. BERTRAND, I.; GODET-GUILLAIN, J. - Dégénérescences cérébelleuses laten-tes chez les cancéreux. Compt. Rend. Soc. Biol., 136:21-22; 664-665, 1942. 2. BERTRAND, I.; TIFFENEAU, R. - Les dégénérescences systematisées centrales dans le coma diabétique. Compt. Rend. Soc. Biol., 136:13-14; 500-501, 1942. 3. BRouWER, B.; BIEMOND, A. - Les affections parenchymateuses du cervelet et leur signification du point de vue de l'anatomie et de la physiologie de cet organe. J. Belge Neurol. et Psychiat., 38:691-757, 138. 4. CAIRO, N. - Elementos de Physiologia, 2* ed. Editora Haupt, Curitiba, 1926. 5. COUJARD, R. - Régulation Neurovégétative de la Croissance et de l'Équilibre Tíssulaires. Vigot Frères, Paris, 1957. 6. GREENFIELD, J. G. - The Spino-Cerebellar Degeneration. Blackwell, Londres, 1954. 7. LEIGH, A. D.; MEYER, A. - Denegeration of the granular layer of the cerebellum. J. Neurol a. Psychiat., 12:287-296, 1949. 8. LESHAN, L.; WORTHINGTON, R. - Personality as a factor in the pathogenesis in human cancer: A review of the literature. Brit. J. M. Psychol., 29:49-56, 1956. 9. MALAMUD, N. - Atlas of Neuropathology. Univ. California Press, 1957. 10. MARANÓN, G. - Manual de Diagnóstico Etiológico, 9a ed. Editora Espasa-Calpe, Madrid, 1956. 11. MILLER, H. - Diseases of the nervous system, cap. 9. In R. Daley; R. Miller: Progress in Clinical Medicine, ed. 3. J. \& A. Churchill Ltd., Londres, 1956. 12. MoRUzzI, G. Problems in Cerebellar Physiology. Charles C. Thomas, Springfield, 1950. 13. RUSSEL BRAIN, W.; DANIEL, P. M.; GREENFIELD, J. G. - Subacute cortical cerebellar degeneration and its relation to carcinoma. J. Neurol, Neurosurg. a. Psychiat., 14: 59-75, 1951. 14. RUSSEL BRAIN, W.; STRAUSS, E. B. - Recent Advances in Neurology and Neuropsychiatry. J. \& A. Churchill Ltd., Londres, 1955. 15. THOMAS, L.; CHODOFF, P. - Translent cerebellar syndrome from extra-cerebral carcinoma. Neurology, 7:370, 1957. 16. ULE, G. - Die systematischen Atrophien des Kleinhirns. In W. Scholz: Erkrankungen des Zentralen Nervensystems, vol. 5, parte 1. Springer Verlag, Berlim, 1957. 17. VIZZOTTO, S.; TOMCHINSKY, R. B.; GOES, J. F.; D'ANDRETTA, V.; FIORE, J. L. A. - Dados preliminares sôbre os resultados com a cloropromazina em Psiquiatria (71 casos). Arq. Assist. Psicopatas do Est. de São Paulo, 21, 1-2:21-49, 1955. 18. YAHN, M.; PUPO, P. P. - Estudo clínico e neuro-histopatológico dos comas pós-hipoglicêmicos no decurso da insulinoterapia pelo método de Sakel. Arq. Assist. Psicopatas do Est. de São Paulo, 6, 1-2:3-75, 1941. 19. ZULCH, K. J. - Pathogénie des atrophies cérébelleuses. Rev. Neurol., $86: 798-800,1952$.

Rua Augusta, 398 - Sĩo Paulo, Brasil. 